\title{
Fracture and Inequality of Digital Skills among Moroccan Ph.D. Students "Hassan II University-Casablanca", as a Case of Study
}

\author{
RedouaneFikri $^{1}$, MalikaTridane ${ }^{1,2}$, Said Belaaouad ${ }^{1}$ \\ ${ }^{1}$ Laboratory of Physical Chemistry of Materials \\ Faculty of Sciences Ben M'sik University Hassan II-Casablanca \\ ${ }^{2}$ Regional Center for Teaching and Professional Training-Casablanca, Morocco \\ fikri.redouane@gmail.com
}

\begin{abstract}
At the present time, the acquisition of digital skills or "e-skills", defined as the ability to master Information and Communication Technologies is essential for the majority of personal, educational and professional activities of Moroccan Ph.D students. How well do doctoral students master basic digital skills? Does faculty membership affect this degree of mastery? In this work, we will draw a brief portrait of the inequalities of digital skills between doctoral students from different faculties of Hassan II Casablanca University, by referring to a baseline of basic digital skills developed with the help of university professors.
\end{abstract}

Keywords: Numerical Inequalities, Second Degree Digital Divide, Numerical Skills, Doctoral Students

Received: 6 June 2019, Revised 10 August 2019, Accepted 30 August 2019

DOI: $10.6025 / \mathrm{jdp} / 2019 / 9 / 4 / 107-111$

(C) 2019 DLINE. All Rights Reserved

\section{Introduction}

Today, there has been a rapid proliferation of digital tools around the world, the concept of digital divide [1], previously centered on the inequalities and the variations of access to technologies through the paradox of the "info-riches" against (the "infopoor") [2] (Brotcorne \& Valenduc, 2008, 9), which seems outdated and criticized in the face of new inequalities appearing and growing around the use of digital tools [3] and concerning differences in skills. Hargittai (2002) the one to mention is "the second degree of digital divide" [4], while access to ICT (first degree fracture) is not the only factor of inclusion or exclusion [5] (Pulzer et al. 2011), since it is the product of the singular encounter of each person with digital cultures [6] (P. Plantard, 2013).

In its definition, "Digital competence involves the safe and critical use of information society technologies at work, in leisure and in communication. The prerequisite is the mastery of ICT: the use of computers to obtain, evaluate, store, produce, present and exchange information, and to communicate and participate via the Internet in collaborative networks". [7] Their acquisition 
seems necessary for the participation in the life of society "[8] (Papi, 2012), and can help to master other key skills, such as communicative and linguistic competences or basic math skills in science.

The variety in usage patterns strongly implies an inequality of digital skills among users, i.e. a difference in the mastery of the skills and knowledge is needed to handle and benefit from digital tools. In this perspective, Wolton" (Wolton, 2003: 32) [9] says that "the same keyboard and the same information is not enough to create equality" (Wolton, 2003: 32) [9]. The key question then becomes not the unequal access to computers, but the unequal ways in which computers are used.

In Morocco since the adoption of the LMD system, several programs to provide students with a master's and doctorate degrees in computer tools have been set up (Injaz, Lawhati ....), as well as the insertion of training modules throughout the first, second and third cycles of university training, in order to give students the necessary skills to confidently and critically use all digital technologies for information, communication and solving basic problems in all aspects of academic and professional life.

To what extent do doctoral students master the digital skills required? Is there a break in digital skills at home? Does faculty membership affect the degree of mastery of these skills?

In this modest work we conducted a sort of evaluation of skills for doctoral students more specifically digital skills, through a process of data collection on the degree of mastery of some basic digital skills already listed in the skills reference, which in turn was elaborated and validated by a number of professors in Hassan II University, Casablanca.

\section{Methodology}

Hassan II University, Casablanca (Ben M'sik campus, Mohammedia and AinChok) is our field of research, mainly the enrolled doctoral students. We conducted a quantitative study using a self-assessment grid developed on the basis of a reference system of digital skills, already developed and validated by a group of university lecturers belonging to Hassan II University, Casablanca, in which the basic digital skills required for any doctoral student of any department or faculty, are four areas of expertise and sixteen competencies.

We took a representative sample of 352 doctoral students, distributed as follows: $170 \mathrm{Ph}$.D. students from the Faculty of Science (FS), 82 Ph.D. Students from the Faculty of Arts and Humanities (FAH), and 100 doctoral students from the Faculty of Economics, Social and Legal and Sciences (FESLS).

To analyze and carry out this work, we used the statistical test of independence chi2 and made a cross analysis, in order to look for the correlation existing between two different variables (the one belonging to a faculty and the degree of mastery of a field of digital skills).

\section{Results and Discussion}

In the following tables, we present for each area of numerical skills the total of the averages of each competency included, expressed by the doctoral students of the three faculties.

For the first area of digital skills D1: Mastery of digital work environment and job security feature the following skills:

C1: Recognize the numerical language and identify the different basic hardware and software elements (Office Automation, Windows ...).

C2: Organize, manipulate, customize and manage your workstation in an autonomous way.

C3: Ensure data protection by securing your workstation against threats and viruses.

Among all Ph.D. students, $35.06 \%$ or 134 of them master this area of expertise very well. The majority of Ph.D. students (42.32\%) or 149 believe its consolidation, while $19.60 \%$ of Ph.D. students or 69 no longer have this competence and seek to acquire it.

There is a link between the two qualitative variables studied, (mastery of the digital skills domain D1 and faculty membership).

\begin{tabular}{llllll}
\hline 108 & Journal of Data Processing Volume & 9 & Number & 4 & December 2019 \\
\hline
\end{tabular}




\begin{tabular}{|c|c|c|c|}
\hline Faculty & Acquired & To consolidate & To acquire \\
\hline FS & 90 & 50 & 30 \\
\hline FAH & 23 & 44 & 15 \\
\hline FESLS & 21 & 55 & 24 \\
\hline Total & 134 & 149 & 69 \\
\hline \multicolumn{4}{|c|}{$(\chi 2=9.488, d d l=4, p=0.0001)$} \\
\hline \multicolumn{4}{|c|}{$\chi 2$ chi-square statistic, $d d l$ Degrees of freedom and $p$ Value } \\
\hline
\end{tabular}

Table 1. Degree of mastery of the first domain of skills D1 FS (Faculty of Sciences), FAH (Faculty of Art and Humanities), FESLS (Faculty of Economics, Social and Legal Sciences)

For the second area of numerical skills D2: Analysis and processing of digital information, the related competencies are:

C4: Develop an information search strategy.

C5: Conduct oriented searches to find articles related to a specific search.

C6: To be able to target by web search the sites allowing establishing communications or making publications according to the expectations.

C7: Analyze, criticize and evaluate the reliability, relevance and credibility of the information found.

C8: Follow and Monitor technological developments in information retrieval.

C9: Evaluate the authenticity of the documentation and the reliability of the sites consulted.

\begin{tabular}{|l|c|c|c|}
\hline Faculty & Under control & To consolidate & To acquire \\
\hline FS & 104 & 55 & 11 \\
\hline FAH & 36 & 39 & 7 \\
\hline FESLS & 32 & 55 & 13 \\
\hline Sum & $\mathbf{1 7 2}$ & $\mathbf{1 4 9}$ & $\mathbf{3 1}$ \\
\hline \multicolumn{4}{|c|}{$(\boldsymbol{2}=\mathbf{2 2 , 8 8 ,} d \boldsymbol{d l}=\mathbf{4 ,} \boldsymbol{p}=\mathbf{0 . 0 0 0 1 3 )}$} \\
\\
\multicolumn{4}{|c|}{$\chi 2$ chi-square statistic,$d d l$ Degrees of freedom and $p$ Value } \\
\hline
\end{tabular}

Table 2. Degree of mastery of the second domain of skills D2 FS Faculty of Sciences, FAH Faculty of Art and Humanities, FESLS Faculty of Economics, Social and Legal Sciences

By analyzing Table 2, we found that a percentage of $48.86 \%$ or 172 of the Ph.D. students already hold the skills of the field, but $42.32 \%$ or 149 of the doctoral students wish to consolidate it and $8.83 \%$ or 31 feel they need to acquire it completely.

The results of the Khi2 test do not make it possible to reject the hypothesis of independence between the mastery of this repertoire of digital skills D2 and faculty membership. 
For the third area of digital skills D3: Communication and exchange of digital information, encompasses the following skills:

C10: Communicate and exchange documents using digital tools.

C11: Contribute and collaborate remotely.

C12: Respect online communication and exchange standards.

C13: To exploit the possibilities of exchange and storage of documents via the Internet.

\begin{tabular}{|l|c|c|c|}
\hline Faculty & Acquired & To consolidate & To acquire \\
\hline FS & 131 & 32 & 7 \\
\hline FAH & 51 & 23 & 8 \\
\hline FESLS & 48 & 47 & 5 \\
\hline Sum & $\mathbf{2 3 0}$ & $\mathbf{1 0 2}$ & $\mathbf{2 0}$ \\
\hline \multicolumn{2}{|c|}{$(\chi \mathbf{2}=\mathbf{1 3 . 2 6 2}, \boldsymbol{d d l}=\mathbf{4 ,} \boldsymbol{p}=\mathbf{0 . 0 1})$} \\
\\
\multicolumn{2}{|c|}{$\chi 2$ chi-square statistic,$d d l$ Degrees of freedom and $p$ Value } \\
\hline
\end{tabular}

Table 3. Degree of mastery of the third domain of skills D3 FS (Faculty of Sciences), FAH (Faculty of Art and Humanities), FESLS (Faculty of Economics, Social and Legal Sciences

Based on the analysis of table 3 above, the proportion of doctoral students mastering the digital skills domain of communication and digital information exchange is 230 or $65.34 \%$. Those who need to consolidate and acquire it totally are $(28.97 \%$ and $5.68 \%)$ 102 and 20 doctoral students respectively.

A dependence between the specific faculty membership variable and the degree of mastery of this digital skills register D3 is recorded.

For the fourth area of digital skills D4: Web Design and Production, defined by the following skills:

C14: Develop and produce a well organized and organized digital document.

\begin{tabular}{|l|c|c|c|}
\hline Faculty & Acquired & To consolidate & To acquire \\
\hline FS & 93 & 60 & 17 \\
\hline FAH & 50 & 20 & 12 \\
\hline FESLS & 64 & 24 & 12 \\
\hline Sum & $\mathbf{2 0 7}$ & $\mathbf{1 0 4}$ & $\mathbf{4 1}$ \\
\hline \multicolumn{2}{|c|}{$(\boldsymbol{\chi 2}=\mathbf{4 . 1 9}, d d l=\mathbf{4 ,} \boldsymbol{p}=\mathbf{0 . 0 1})$} \\
\\
\multicolumn{2}{|c|}{$\chi 2$ chi-square statistic, $d d l$ Degrees of freedom and $p$ Value } \\
\hline
\end{tabular}

Table 4. Degree of mastery of the fourth area of digital skills D4 FS (Faculty of Sciences), FAH (Faculty of Art and Humanities), FESLS (Faculty of Economics Social and Legal Sciences 
C15: Publish and broadcast on the web.

C16: Apply licenses and reproduction rights.

The results obtained in the table show that $207 \mathrm{Ph} . \mathrm{D}$ students $(58.80 \%)$ announce that this domain of skills is acquired, 104 of them $(29.54 \%)$ express their need for consolidation and a minority of 41 doctoral students $(11.64 \%)$ declare their lack of these skills.

No dependence between the faculty membership variable and the degree of mastery of this D4 skill field is recorded.

\section{Conclusion}

The fracture resulting from inequalities of acquisition/mastering digital skills between doctoral students at Hassan II University, Casablanca is clearly obvious yet not alarming. However, it does not prevent to reduce by working on the development of skills to understand the challenges of digital, and among others it is necessary. We should translate the repository on which we have worked in training repository and educational content, propose specific evaluation methods for digital skills during doctoral registration, develop training modules on digital skills since the first year of the doctoral cycle, set up in consultation with the heads of all the faculties of Hassan II University a path of numerical skills for Ph.D. students through complementary doctoral training courses. Finally, developing an interactive platform for evaluating and valuing the digital skills of Ph.D students is necessary and it is worth noticing that digital skills are still in motion. They should be improved and updated to easily adapt to new technological developments.

\section{References}

[1] Salmi, L. R. (2001). Principes de la communication orale scientifique: comment passer d'une bonne étude à une bonne présentation orale. Revue Médicale de l'Assurance Maladie. 2001 avril-juin; 32, 83-92.

[2] Bassiri, M., Boulahouajeb, A., Aichi, Y., Belaaouad, S., Radid, M. (2018). Distance learning - A powerful vector of the enhancement of socio-professional competences: Case of the training of contract teachers in Regional Centre of Training and Education, Morocco. Asia Life Sciences. 16(1) 11-19.

[3] Bassiri, M., Marouane, S., Tridane, M., Belaaouad, S., Radid, M. (2018). Alternating training and organizational learning: From an ambivalent relationship towards the development of a reflexive and metacognitive practice. Asia Life Sciences. 16(1) 205-215.

[4] Pitchai, B., Mohammed, N. I., Gowraganahalli, J. (2013). The basic concepts of scientific research and communication. Journal of Pharmacology \& Pharmacotherapeutics. 4 (2) 130-138.

[5] Paul Glover. (2008). Guide de communication scientifique orale, l’Association francophone pour le savoir; 29 aout 2008. P 25.

[6] Zerraf, S., Zain, S., Khyati, A., Tridane, M., Belaaouad, S. (2019). A pedagogical approach to educational communication in the educational context. International Journal of Advanced Education and Research. (January) 4(1) 01-04.

[7] Papi, C. (2012). Des référentiels à la validation des compétences numériques : questionnements et dispositifs, Questions Vives [Online], 7(17) 2012, Online since 15 September 2012, connection on 16 October 2018. URL: http://journals.openedition. org/questionsvives/986.

[8] Dominique, W. (2003). Fracture numérique ou facture numérique?, in Jauréguiberry F. et Proulx S., Internet, nouvel espace citoyen ?, Paris, l'Harmattan, pp. 31-35 inHoussein; Les personnes âgées et la fracture numérique de « second degré » : 1'apport de la perspective critique en communication repéré sur : https://journals.openedition.org/rfsic/1294?lang=fr

[9] Warschauer, M. (2003). Technology and social inclusion. Rethinking the digital divide. MIT Press. Massachusetts. p. 46. 